\title{
Txe, an endoribonuclease of the enterococcal Axe-Txe toxin-antitoxin system, cleaves mRNA and inhibits protein synthesis
}

\section{Correspondence \\ Paul J. Hergenrother \\ hergenro@uiuc.edu}

Received 16 September 2010

Revised 15 October 2010

Accepted 25 October 2010

\author{
Elizabeth M. Halvorsen, ${ }^{1}$ Julia J. Williams, ${ }^{1}$ Azra J. Bhimani, ${ }^{1,2}$ \\ Emily A. Billings ${ }^{1,2}$ and Paul J. Hergenrother ${ }^{2,3}$
}

${ }^{1}$ Department of Microbiology, University of Illinois at Urbana-Champaign, 600 S. Mathews Ave., Urbana, IL 61801, USA

${ }^{2}$ Department of Biochemistry, University of Illinois at Urbana-Champaign, 600 S. Mathews Ave., Urbana, IL 61801, USA

${ }^{3}$ Department of Chemistry, University of Illinois at Urbana-Champaign, 600 S. Mathews Ave., Urbana, IL 61801, USA

The axe-txe operon encodes a toxin-antitoxin (TA) pair, Axe-Txe, that was initially identified on the multidrug-resistance plasmid pRUM in Enterococcus faecium. In Escherichia coli, expression of the Txe toxin is known to inhibit cell growth, and co-expression of the antitoxin, Axe, counteracts the toxic effect of Txe. Here, we report the nucleotide sequence of pS177, a $39 \mathrm{~kb}$ multidrugresistant plasmid isolated from vancomycin-resistant Ent. faecium, which harbours the axe-txe operon and the vanA gene cluster. RT-PCR analysis revealed that the axe-txe transcript is produced by strain $\mathrm{S} 177$ as well as by other vancomycin-resistant enteroccoci. Moreover, we determine the mechanism by which the Txe protein exerts its toxic activity. Txe inhibits protein synthesis in E. coli without affecting DNA or RNA synthesis, and inhibits protein synthesis in a cell-free system. Using in vivo primer extension analysis, we demonstrate that Txe preferentially cleaves single-stranded mRNA at the first base after an AUG start codon. We conclude that Txe is an endoribonuclease which cleaves mRNA and inhibits protein synthesis.

\section{INTRODUCTION}

Enterococcal species such as Enterococcus faecium and Enterococcus faecalis have emerged as significant nosocomial pathogens throughout Europe and the United States. These bacteria are increasingly responsible for a variety of illnesses, particularly in immunocompromised patients, and are one of the main causes of surgical-site infections (Hidron et al., 2008; Owens \& Stoessel, 2008; Richards et al., 2000). Clinical isolates of enterococci are often resistant to multiple antibiotics either intrinsically or through the lateral gene transfer of antibiotic resistance determinants, the most problematic of which are the genetic elements that encode vancomycin resistance (Baldassarri et al., 2005; Deshpande et al., 2007; Dowzicky \& Park, 2008;

Abbreviations: PNK, polynucleotide kinase; TA, toxin-antitoxin; TCA, trichloroacetic acid; VRE, vancomycin-resistant enterococci.

The GenBank/EMBL/DDBJ accession number for the sequence of plasmid pS177 reported in this paper is HQ115078.

Three supplementary figures, showing protein synthesis following IPTG induction of $\mathrm{Txe}_{\mathrm{H}}-\mathrm{His}_{6}, \mathrm{Axe}-\mathrm{His}_{6}$ and empty $\mathrm{pET} 21 \mathrm{a}$ vector, and the effect of Txe-His 6 expression in Escherichia coli Rosetta BL21(DE3), are available with the online version of this paper.
Guardabassi \& Dalsgaard, 2004; Low et al., 2001; Sader \& Jones, 2009; Werner et al., 2008). A recent survey of Grampositive pathogens isolated from hospitals in the United States found that, for between 2002 and 2008, up to $33 \%$ of enterococcal species tested as part of the surveillance network were vancomycin-resistant enterococci (VRE) (JMI, 2009). As vancomycin is a preferred antimicrobial treatment for enterococcal infections, the increasing occurrence of multidrug-resistant VRE severely limits therapeutic options and highlights the need for new antibiotics.

In the search for novel antimicrobial agents, one intriguing approach involves the explicit targeting of toxin-antitoxin (TA) systems to exploit their innate toxicity (DeNap \& Hergenrother, 2005; Engelberg-Kulka et al., 2004; Williams \& Hergenrother, 2008). TA genes were originally discovered on plasmids, where they function as plasmid maintenance systems (Ogura \& Hiraga, 1983). In plasmids containing the genes for proteic (type II) TA systems, a stable toxin and a labile antitoxin are encoded in a single operon. In a cell carrying the plasmid, both proteins are expressed and the antitoxin binds to and inhibits the toxin. However, if during cell division a plasmid-free segregant arises, the labile antitoxin is rapidly degraded, freeing the 
toxin to kill the cell (Aizenman et al., 1996; Hayes, 2003). This post-segregational killing has led TA systems to be dubbed 'plasmid addiction' systems, as the cell will die if the plasmid is lost (Gerdes et al., 1986). The first TA system identified was $c c d A B$, on the F plasmid of Escherichia coli (Ogura \& Hiraga, 1983), and since its discovery, a number of TA systems have been identified on a variety of plasmids and bacterial chromosomes (Moritz \& Hergenrother, 2007a; Pandey \& Gerdes, 2005; Sletvold et al., 2007). Among the type II TA systems, the toxins can be grouped into several superfamilies based on sequence and structural homology, including the RelE/ParE, MazF/CcdB, Doc, HipA, $\zeta$ and PIN domain superfamilies, and most have been shown to act as either endoribonucleases (also termed mRNA interferases) or inhibitors of DNA gyrase (Anantharaman \& Aravind, 2003; Bernard \& Couturier, 1992; Christensen-Dalsgaard \& Gerdes, 2008; ChristensenDalsgaard et al., 2008; Fico \& Mahillon, 2006; Francuski \& Saenger, 2009; Jiang et al., 2002; Makarova et al., 2009; Miallau et al., 2009; Van Melderen, 2002).

Reports of TA systems in Gram-positive bacteria have been much rarer compared with the numerous studies of TA systems in Gram-negative bacteria. One of the first proteic TA systems described in a Gram-positive organism was the Axe-Txe system, which was identified on the $24.8 \mathrm{~kb}$ nonconjugative plasmid pRUM, obtained from a multidrugresistant clinical isolate of Ent. faecium (Grady \& Hayes, 2003). pRUM confers resistance to chloramphenicol, erythromycin, streptomycin and streptothricin, and coexists in its host with a $60 \mathrm{~kb}$ conjugative vancomycin resistance plasmid. Sequence analysis of pRUM suggested it arose from a variety of mobile genetic elements, recombination events and smaller plasmids (Grady \& Hayes, 2003). Although it was originally described in 2003 , there have been no further reports on the biochemical characterization of Axe-Txe.

We have previously shown that in a collection of 75 VRE clinical isolates, 56 contained the genes for axe-txe, as determined by PCR analysis (Moritz \& Hergenrother, 2007a). Of those 56 isolates, gel extractions and conjugative matings suggested a physical linkage between the vancomycin-resistance genes and the axe-txe genes in 44 isolates (Moritz \& Hergenrother, 2007a). Recently, a separate analysis of a collection of Ent. faecium isolates found that of 42 strains positive by PCR for the pRUM replicon type, $90 \%$ were also PCR-positive for axe-txe (Rosvoll et al., 2010). Additionally, co-hybridization studies suggested that a genetic linkage existed between the pRUM replicon and the axe-txe genes (Rosvoll et al., 2010). Thus, the axetxe genes appear to be common features of plasmids in enterococci where they may play a role in the persistence and stability of plasmid-encoded antibiotic resistance, including vancomycin resistance.

Although several TA systems have been well characterized biochemically, many of these were discovered on the chromosomes of Gram-negative bacteria (Christensen et al., 2001; Engelberg-Kulka \& Glaser, 1999). In contrast, there is a relative paucity of studies on TA systems of Gram-positive origin, and TA systems that were discovered on multidrug resistance plasmids. As the dissemination of such plasmids enables widespread resistance to antibiotics, the mechanisms by which these plasmids maintain themselves in their hosts are of critical importance. The development of toxin activation strategies for Grampositive bacteria requires the identification of a suitable TA system that is functional in these hosts, and information about the mechanism of action of the toxin.

In this study, we report the nucleotide sequence of plasmid

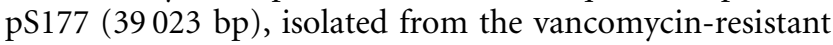
Ent. faecium clinical isolate S177. pS177 confers resistance to kanamycin, streptothricin, streptomycin, erythromycin and vancomcyin and harbours the genes for axe-txe and a relBE homologue, relBE $E_{E f}$. Additionally, we confirmed by RT-PCR analysis that the axe-txe transcript is synthesized in six VRE clinical isolates, including strain S177. Although axe-txe has been shown to function as a plasmid stabilization system in Ent. faecium, Bacillus thuringiensis and E. coli (Grady \& Hayes, 2003), the mechanism by which Txe elicits its toxic effect on the cell is unknown. Here, we demonstrate that expression of the toxin inhibits protein synthesis in the cell but does not affect DNA or RNA synthesis. Primer extension analysis reveals that Txe is an endoribonuclease that cleaves cellular RNA three bases downstream of an AUG start codon. This is the first report, to our knowledge, of the biochemical mode of action of Txe, and one of the few studies on TA systems of Grampositive origin.

\section{METHODS}

Plasmid DNA isolation. Plasmid DNA was isolated from Ent. faecium by using a modified alkaline lysis midiprep protocol (Sambrook \& Russell, 2001). A $50 \mathrm{ml}$ bacterial culture grown in brain heart infusion broth was harvested after 12-14 h growth and the pellet was resuspended in $2 \mathrm{ml}$ solution I (25 mM Tris, $\mathrm{pH} 8.0,50 \mathrm{mM}$ glucose, $10 \mathrm{mM}$ EDTA) and $200 \mu \mathrm{l}$ lysozyme $\left(100 \mathrm{mg} \mathrm{ml}^{-1}\right.$ in $25 \mathrm{mM}$ Tris, $\mathrm{pH}$ 8.0). The suspension was incubated at $37^{\circ} \mathrm{C}$ for $1 \mathrm{~h}$. Solution II ( $3 \mathrm{ml} ; 0.2 \mathrm{M} \mathrm{NaOH}, 1 \% \mathrm{SDS}$ ) was added and the tube was inverted gently six times, followed by $4.5 \mathrm{~min}$ incubation on ice. Finally, $3 \mathrm{ml}$ solution III ( $5 \mathrm{M}$ potassium acetate, $11.5 \%$ glacial acetic acid) was added and the tube was inverted eight times, followed by $5 \mathrm{~min}$ incubation on ice. Cell debris was collected by centrifuging for $20 \mathrm{~min}$ at $20000 \mathrm{~g}$ at $4{ }^{\circ} \mathrm{C}$. To extract the nucleic acid, $7 \mathrm{ml}$ supernatant was transferred to a new tube and an equal volume of phenol/chloroform/ isoamyl alcohol (25:24:1, w/v/v) was added and the tube was shaken vigorously, followed by centrifugation as described previously. Nucleic acid was precipitated from $6 \mathrm{ml}$ of the aqueous layer by adding an equal volume of 2-propanol and incubating at room temperature for $2 \mathrm{~min}$, followed by centrifuging for $30 \mathrm{~min}$ at $27000 \mathrm{~g}$. The nucleic acid pellet was washed with $5 \mathrm{ml} 70 \%$ ethanol and centrifuged for $10 \mathrm{~min}$ at $27000 \mathrm{~g}$ at $4{ }^{\circ} \mathrm{C}$. All ethanol was removed and the pellet was allowed to air-dry, then dissolved in $100 \mu \mathrm{l} 10 \mathrm{mM}$ Tris, $\mathrm{pH} 8.0$, overnight at $4{ }^{\circ} \mathrm{C}$. The RNA was digested by incubation with $5 \mu \mathrm{l}$ $10 \mathrm{mg}$ RNase $\mathrm{A} \mathrm{ml}^{-1}$ for $30 \mathrm{~min}$ at $37^{\circ} \mathrm{C}$.

Plasmid DNA isolated from Ent. faecium S177 was separated by electrophoresis in a $0.65 \%$ agarose gel, containing $0.5 \mu \mathrm{g}$ ethidium 
bromide $\mathrm{ml}^{-1}$. The dominant supercoiled plasmid band was excised from the gel and the DNA was recovered by electroelution, following a modification of the protocol described by Strong et al. (1997). Dialysis tubing with a $12-14 \mathrm{kDa}$ nominal molecular mass cut-off (Spectra/Por) was prepared by boiling in $25 \mathrm{mM}$ EDTA, $\mathrm{pH}$ 8.0, for $15 \mathrm{~min}$, rinsed thoroughly in $\mathrm{dH}_{2} \mathrm{O}$, and rinsed in $1 \times$ Tris-acetateEDTA (TAE) at $4{ }^{\circ} \mathrm{C}$. The gel slice and approximately $2 \mathrm{ml} 1 \times \mathrm{TAE}$ were secured in the dialysis tubing and electrophoresed in $1 \times \mathrm{TAE}$ at $70 \mathrm{~V}$ for $2 \mathrm{~h}$, at which point the polarity was reversed for $2 \mathrm{~min}$. Without removing the gel slice, the solution was subjected to dialysis against $10 \mathrm{mM}$ Tris, $\mathrm{pH} 8.0$, overnight at $4{ }^{\circ} \mathrm{C}$. The electroeluted plasmid DNA was concentrated by centrifuging at $500 \mathrm{~g}$ in a $0.5 \mathrm{ml}$ $30 \mathrm{kDa}$ molecular mass cut-off tube (Microcon) until the volume was reduced to $100 \mu \mathrm{l}$.

Plasmid DNA sequencing. Shotgun cloning, sequencing and assembly of plasmid pS177 was performed by the University of Illinois W.M. Keck Center for Comparative and Functional Genomics. Briefly, DNA was sheared with a nebulizer, end-repaired and dephosphorylated. The DNA was separated by electrophoresis in a $0.8 \%$ low-melting-point agarose gel, from which DNA ranging from 1.5 to $5.0 \mathrm{~kb}$ was purified and cloned into the pSMART-HCKan vector (Lucigen) according to the manufacturer's instructions. Sequencing was performed on 480 subclones from both the $5^{\prime}$ and the $3^{\prime}$ ends of the insert by using ABI Big-Dye terminator chemistry (Applied Biosystems). Custom primers were used in PCRs and sequencing reactions to close gaps and to ensure at least $3 \times$ coverage at each nucleotide (average coverage was $12.4 \times$ ). Sequence data were assembled by using the Phrap (http://www.phrap.org) and Sequencher (GeneCodes) software programs. Analysis of the assembled plasmid via the BLAST program (Altschul et al., 1990) was used to determine sequence similarity, and annotations were made accordingly.

Plasmid construction. To construct plasmid pET21a-txe-His ${ }_{6}$, the txe gene was amplified by PCR with primers txe-NheI-F, $5^{\prime}$ CATCCCGCTAGCATGATTAAGG-3', and txe-XhoI-R, 5'-CGCCCTCGAGTTCATAGTG-3'. The PCR product was digested with NheI and XhoI and inserted into pET21a (Novagen) digested with NheI and XhoI. $\mathrm{His}_{6}-$ Txe is expressed from pET21a-txe-His ${ }_{6}$ upon addition of IPTG to E. coli Rosetta BL21(DE3).

To construct plasmid pACYCDuet1-His 6 -axe, the axe gene was amplified by PCR with primers axe-start-EcoRI, 5'-GGGTGAATTCAATGGAAGCA-3', and axe-stop-SalI, 5'-TCAGACTGCGACTTAATCATC-3'. The PCR product was digested with EcoRI and SalI and inserted into pACYCDuet1 (Novagen) digested with EcoRI and SalI. His ${ }_{6}-$ Axe is expressed from pACYCDuet1-His ${ }_{6}$-axe upon addition of IPTG to E. coli BL21(DE3) or Rosetta BL21(DE3).

To construct plasmid pET21a-axe-His 6 , the axe gene was amplified by PCR with primers axe-cterm-F1, 5'-CCAGGATCCGCATATGATGGAAGC-3', and axe-XhoI-R, 5'-CAAGCTCGAGGACTTCATCATC-3'. The PCR product was digested with NdeI and XhoI and inserted into pET21a (Novagen) digested with NdeI and XhoI. Axe$\mathrm{His}_{6}$ is expressed from pET21a-axe-His 6 upon addition of IPTG to $E$. coli BL21(DE3) or Rosetta BL21(DE3).

To construct plasmid pET28a-relB-His 6 , relB was amplified by PCR with primers relB-NcoI-F2, 5'-GGAGATATACCATGGGAACAATGG-3', and relB-HindIII-R, 5'-CCAGAAAAGCTTCCATCCGAGTTC-3'. The PCR product was digested with NcoI and HindIII and inserted into pET28a treated with $\mathrm{NcoI}$ and HindIII. pET28a-relBEHis $_{6}$ produces RelB-His 6 upon addition of IPTG to E. coli BL21(DE3).

To construct plasmid pRSF-1b-His ${ }_{6}-l p p$, the $l p p$ gene was amplified by PCR with primers $l p p-1-B a m H I, 5^{\prime}$-CCCCGGATCCGGAGATTA-
ACTCAATCTAGAGG-3', and lpp-2-SalI, 5'-CCCCGTCGACGCGCCATTTTTCACTTCACAG- ${ }^{\prime}$. The PCR product was digested with BamHI and SalI and inserted into pRSF-1b (Novagen) digested with BamHI and SalI. His $_{6}-\mathrm{Lpp}$ is expressed from pRSF-1b-His 6 -lpp upon addition of IPTG to E. coli Rosetta BL21(DE3) or E. coli BL21(DE3) cells.

Macromolecular synthesis assays. For each strain tested, an overnight culture grown in Luria-Bertani (LB) with $100 \mu \mathrm{g}$ ampicillin $\mathrm{ml}^{-1}$ was used to seed $10 \mathrm{ml}$ filter-sterilized M9 broth $(42 \mathrm{mM}$ $\mathrm{Na}_{2} \mathrm{HPO}_{4}, 24 \mathrm{mM} \mathrm{KH_{2 }} \mathrm{PO}_{4}, 9 \mathrm{mM} \mathrm{NaCl}, 19 \mathrm{mM} \mathrm{NH} \mathrm{NH}_{4} \mathrm{Cl}, 0.5 \%$ glucose, $1 \%$ Casamino acids) and shaken at $37^{\circ} \mathrm{C}$ until an $\mathrm{OD}_{600}$ of 0.3 was reached. To measure protein synthesis, $\left[{ }^{3} \mathrm{H}\right]$ leucine $(\mathrm{L}-[3,4$, $\left.5-{ }^{3} \mathrm{H}(\mathrm{N})\right]$ leucine; PerkinElmer) was added to the culture at a final concentration of $2 \mu \mathrm{Ci} \mathrm{ml}^{-1}\left(74 \mathrm{kBq} \mathrm{ml}^{-1}\right)$ and shaken at $37{ }^{\circ} \mathrm{C}$ for $5 \mathrm{~min}$. To measure DNA synthesis, $\left[{ }^{3} \mathrm{H}\right]$ thymidine $\left(\left[6-{ }^{3} \mathrm{H}\right]\right.$ thymidine; PerkinElmer) was added to the culture at a final concentration of $0.1 \mu \mathrm{Ci} \mathrm{ml}{ }^{-1}\left(3.7 \mathrm{kBq} \mathrm{ml}^{-1}\right)$ and shaken at $37^{\circ} \mathrm{C}$ for $1 \mathrm{~min}$. To measure RNA synthesis, $\left[{ }^{3} \mathrm{H}\right]$ uridine $\left(\left[5,6-{ }^{3} \mathrm{H}\right]\right.$ uridine; PerkinElmer) was added to the culture at a final concentration of $0.1 \mu \mathrm{Ci} \mathrm{ml} l^{-1}$ $\left(3.7 \mathrm{kBq} \mathrm{ml}^{-1}\right.$ ) and shaken at $37^{\circ} \mathrm{C}$ for $1 \mathrm{~min}$.

Before inducing expression, $0.5 \mathrm{ml}$ was taken from the culture and added to $1 \mathrm{ml}$ cold $15 \%$ trichloroacetic acid (TCA), inverted once and placed on ice for at least $30 \mathrm{~min}$ to precipitate (via TCA) all macromolecules in the cell. The remaining culture was split in two; one half received $0.05 \mathrm{mM}$ IPTG and the other received no IPTG. The cultures were shaken again at $37{ }^{\circ} \mathrm{C}$ and aliquots were TCAprecipitated, as above, 60, 120 and $180 \mathrm{~min}$ after IPTG was added. Precipitates were filtered on a glass microfibre disc (Whatman or Fisher Scientific), washed twice with cold $100 \%$ ethanol and allowed to dry overnight. Discs were placed in scintillation fluid and c.p.m. was measured.

Cell-free protein synthesis assays. The $\mathrm{S} 30 \mathrm{~T} 7$ high-yield protein expression system (Promega) was used for cell-free protein synthesis according to the manufacturer's protocol with some modifications. The construct encoding the protein of interest, namely pET21-txe$\mathrm{His}_{6}$, pET21a-axe-His ${ }_{6}$ or pET21a-His ${ }_{6}$-axe, was incubated with $10 \mu \mathrm{l}$ S30 Premix Plus and $9 \mu \mathrm{l}$ T7 S30 extract (at $37{ }^{\circ} \mathrm{C}$ for $20 \mathrm{~min}$ ) to allow synthesis of Txe- $\mathrm{His}_{6}$, Axe-His ${ }_{6}$ or $\mathrm{His}_{6}-$ Axe. After the initial $20 \mathrm{~min}$ of incubation, $300 \mathrm{ng}$ DNA (10 mM Tris/HCl, pH 8.0) encoding the reporter protein (pET28a-relB-His ${ }_{6}$ or pRSF1b-His $6^{-}$ $l p p$ ) was added and shaken at $37^{\circ} \mathrm{C}$ for $1 \mathrm{~h}$. Reactions were stopped by placing tubes on ice for $5 \mathrm{~min}$ and by adding $1 \mu \mathrm{g}$ RNase A to each tube and incubating at room temperature for $5 \mathrm{~min}$.

Protein was isolated from each reaction by precipitation with cold $10 \%$ TCA, followed by centrifugation at $21130 \mathrm{~g}$ for $15 \mathrm{~min}$ at room temperature. Pellets were washed with cold $100 \%$ ethanol and allowed to air-dry. Pellets were resuspended in $30 \mu \mathrm{l} 50 \mathrm{mM}$ Tris/ $\mathrm{HCl}, \mathrm{pH} 8.0,300 \mathrm{mM} \mathrm{NaCl}$ and $20 \mu \mathrm{l} 6 \times$ SDS loading dye and heated at $95{ }^{\circ} \mathrm{C}$ for $5 \mathrm{~min}$. For each sample, the entire volume was run on a $15 \%$ polyacrylamide Tris/ $\mathrm{HCl}$ precast gel (Bio-Rad). After SDS-PAGE, proteins were transferred to an Immobilon-P PVDF membrane (Millipore) in cold Towbin transfer buffer. Membranes were blocked with PBS containing 5\% BSA and $0.05 \%$ Tween-20 overnight with gentle shaking at $4{ }^{\circ} \mathrm{C}$. Membranes were probed with HisProbe-HRP (Pierce) at $1 \mu \mathrm{g} \mathrm{ml}^{-1}$ in PBS with $0.05 \%$ Tween-20 for $1 \mathrm{~h}$ at room temperature. Antibody binding was detected with Supersignal West Pico chemiluminescent substrate (Pierce), followed by exposure to autoradiography film.

RNA extraction and RT-PCR analysis. Total RNA from enterococci was isolated in a manner identical to the extraction method described previously (Moritz \& Hergenrother, 2007a). Intragenic primers used for axe-txe RT-PCR analysis were designed from the sequence of the plasmid pRUM. The primers used were axe-txe-RT-F, 
5'-CAGTAGCTTATTCAAATTTCCGCC-3', and axe-txe-RT-R, 5'GTTCATCTGTAATTCTTCTGGACC-3' . Control primers were based on the $t u f$ gene specific to enterococcal species (Garcia-Migura et al., 2007). The primers used were Ent-tuf F, 5'-TACTGACAAACCATTCATGATG-3', and Ent- $t$ uf R, 5-'AACTTCGTCACCAACGCGAAC-3'. RT-PCR and PCR for DNA contamination were performed by using the SuperScript One-Step RT-PCR with Platinum Taq kit (Invitrogen) as described previously (Moritz \& Hergenrother, 2007a). RT-PCR amplification products were analysed by agarose gel electrophoresis in $1 \%$ agarose and were stained with ethidium bromide.

Primer extension analysis. Primer lpp 21 (5'-CTGAACGTCAGAAGACAGCTGATCG-3') (Christensen et al., 2003) was $5^{\prime}$-endlabelled with $\left[\gamma^{32} \mathrm{P}\right] \mathrm{ATP}$ according to a modification of the protocol reported by Kitami \& Hiwada (1999). In a $10 \mu \mathrm{l}$ reaction volume, 10 pmol of the lpp 21 primer was mixed with $1 \mu \mathrm{l} 10 \times \mathrm{T} 4$ polynucleotide kinase (PNK) reaction buffer (NEB), $1 \mu 110 \mathrm{U}$ T4 PNK (NEB) $\mathrm{ml}^{-1}$ and $3 \mu \mathrm{l}\left[\gamma_{-}{ }^{32} \mathrm{P}\right] \mathrm{ATP}\left[6 \mathrm{mCi} \mathrm{mmol}^{-1}(222 \mathrm{MBq}\right.$ $\left.\mathrm{mmol}^{-1}\right), 10 \mathrm{mCi} \mathrm{ml}^{-1}\left(370 \mathrm{MBq} \mathrm{ml}^{-1}\right)$ or adjusted appropriately for decay]. The reaction mixture was incubated at $37^{\circ} \mathrm{C}$ for $30 \mathrm{~min}$ followed by $2 \mathrm{~min}$ at $90{ }^{\circ} \mathrm{C}$ to inactivate the enzyme. Unincorporated nucleotides were removed with a NucAway Spin column according to the manufacturer's protocol (Ambion). The final concentration of the

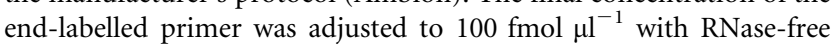
$\mathrm{dH}_{2} \mathrm{O}$.

The DNA sequencing ladder was prepared with the primer $\operatorname{lpp} 21$ and pRSF-1b-His ${ }_{6}-l p p$ as template to map the $5^{\prime}$-end of the $l p p$ mRNA. Sequencing reactions were prepared by using the Sequenase version 2.0 DNA sequencing kit and $\left[\alpha-{ }^{32} \mathrm{P}\right] \mathrm{dATP}$ according to the manufacturer's protocol (USB).

E. coli Rosetta BL21(DE3) carrying pET21-txe-His 6 was grown in LB containing $100 \mu \mathrm{g}$ ampicillin $\mathrm{ml}^{-1}$ to an $\mathrm{OD}_{600}$ of 0.3 . Before adding $0.5 \mathrm{mM}$ IPTG, a $1 \mathrm{ml}$ aliquot was centrifuged for $5 \mathrm{~min}$ at room temperature and the pellet was frozen at $-80{ }^{\circ} \mathrm{C}$. Following addition of IPTG, aliquots were also taken at 30, 60 and 120 min postinduction. RNA was extracted by using the RNeasy mini kit for isolation of total RNA from bacteria and treated with RNase-free DNase (Qiagen). The ${ }^{32} \mathrm{P}$-labelled lpp 21 primer was hybridized with $10 \mu \mathrm{g}$ total RNA from each time point according to a modification of the protocol reported by Kitami \& Hiwada (1999). In a $40 \mu \mathrm{l}$ reaction volume, $10 \mu \mathrm{g}$ total RNA, $200 \mathrm{fmol}{ }^{32} \mathrm{P}$-labelled $l p p 21$ primer, $4 \mu \mathrm{l}$ $10 \times$ avian Myeloblastosis virus reverse transcriptase (AMV RT) reaction buffer $(\mathrm{NEB})$ and $4 \mu \mathrm{l} 10 \times \mathrm{dNTP}$ solution $(10 \mathrm{mM}$ each dNTP) were added together. The reaction mixture was heated at $90{ }^{\circ} \mathrm{C}$ for $2 \mathrm{~min}$ and then incubated at $54{ }^{\circ} \mathrm{C}$ overnight $(18-20 \mathrm{~h})$.

The next day, $20 \mu \mathrm{l}$ of a primer extension mastermix $(6 \mu \mathrm{l} 10 \times \mathrm{AMV}$ RT reaction buffer, $6 \mu \mathrm{l} 10 \times$ dNTP solution, $4.2 \mu \mathrm{l} 40 \mathrm{mM}$ sodium

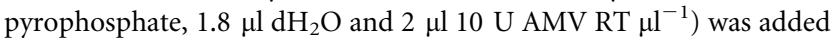
to each hybridization reaction, mixed gently and incubated at $42{ }^{\circ} \mathrm{C}$ for $1 \mathrm{~h}$. Reactions were then treated with $2 \mu 10 \mathrm{mg} \mathrm{RNase} \mathrm{A} \mathrm{ml}^{-1}$ at $37{ }^{\circ} \mathrm{C}$ for $30 \mathrm{~min}$ and extracted twice with phenol/chloroform/ isoamyl alcohol $(25: 24: 1, \mathrm{w} / \mathrm{v} / \mathrm{v})$. DNA was precipitated by adding 0.1 vols $3 \mathrm{M}$ sodium acetate, $\mathrm{pH} 5.5$, and 2.5 vols $70 \%$ ethanol and storing at $-80{ }^{\circ} \mathrm{C}$ for $30 \mathrm{~min}$. Precipitates were centrifuged at room temperature for $15 \mathrm{~min}$, washed with $70 \%$ ethanol and allowed to air-dry before resuspending in $10 \mu$ stop solution (USB).

Gel analysis was performed by using a $6 \%$ polyacrylamide TBE-urea gel prepared with $6 \%$ PAGE/urea and complete buffer solutions (Ambion). The gel was pre-electrophoresed at $45 \mathrm{~W}$ in $1 \times$ Trisborate-EDTA (TBE) buffer for $30 \mathrm{~min}$. Primer extension samples $(10 \mu \mathrm{l})$ were heated at $90{ }^{\circ} \mathrm{C}$ for $5 \mathrm{~min}$ before loading onto the gel, and the ${ }^{32} \mathrm{P}$-labelled sequencing reactions $(2 \mu \mathrm{l})$ were heated at $75{ }^{\circ} \mathrm{C}$ for 2 min before loading onto the gel. After running the gel at $45 \mathrm{~W}$ in $1 \times$ TBE buffer, it was dried under vacuum at $80{ }^{\circ} \mathrm{C}$ for $1 \mathrm{~h}$. The gel was cooled before exposing to a storage phosphor screen cassette (Molecular Dynamics) at room temperature overnight. Primer extension products and the DNA sequencing ladder were detected by using the Storm PhosphorImager 840 (Molecular Dyanmics/GE Lifesciences).

\section{RESULTS}

Although it has been suggested that activation of toxins of TA pairs could be a viable antibacterial strategy, the success of such an approach is dependent on the TA system being present and functional in the bacteria of interest (Williams \& Hergenrother, 2008). The axe-txe operon has been shown to reside on plasmids within VRE (Moritz \& Hergenrother, 2007a; Rosvoll et al., 2010), although PCR alone was used to characterize axe-txe in these studies. In an effort to link axe-txe definitively to plasmid-encoded vancomycin resistance genes and to establish the functionality of axe-txe within VRE, we first sought to characterize fully an enterococcal plasmid harbouring axe-txe, and to determine if VRE clinical isolates synthesize the axe-txe mRNA transcript. For this, a collection of VRE clinical isolates previously shown to harbour a plasmid with axetxe was used (Moritz \& Hergenrother, 2007a).

\section{Sequence analysis of pS177}

The nucleotide sequence of plasmid pS177 was determined by shotgun cloning and sequencing, with average coverage of $12.4 \times$. pS177 is a $39032 \mathrm{bp}$ non-conjugative plasmid isolated from Ent. faecium clinical strain S177. Its DNA $\mathrm{G}+\mathrm{C}$ content is $35.5 \mathrm{~mol} \%$, consistent with that of other enterococcal plasmids and genomes (Sletvold et al., 2007). Nucleotide BLAST analysis of pS177 revealed that 37358 bp $(95.7 \%)$ shared significant $(99-100 \%)$ similarity with sequences deposited in the GenBank database (Altschul et al., 1990). Forty ORFs were identified and annotated based on these known sequences. For ORFs annotated in the database as hypothetical proteins, BLASTP searches were performed to assign a putative function for that potential protein based on amino acid similarity (Altschul et al., 1990). pS177 has a mosaic structure comprising a pRUM backbone, two resistance gene cassettes and five insertion elements (Fig. 1, Table 1). Interestingly, pS177 has 12748 bp (32.6\%) and 18930 bp (48.4\%) in common with plasmids p5753cA (GenBank accession no. GQ900435) and p5753cB (GenBank accession no. GQ900487), respectively, both isolated from Ent. faecium.

pS177 shares $12341 \mathrm{bp}$ (31.6\%) of its sequence with pRUM and contains $75 \%$ of the total pRUM plasmid (GenBank accession no. AF50797). It harbours a pRUMlike replicon consisting of the putative RepA replication protein observed in various enterococcal plasmids (Grady \& Hayes, 2003; Rosvoll et al., 2010). In addition to genes encoding stability mechanisms such as plasmid replication and partitioning, pS177 carries the TA system axe-txe (Grady \& Hayes, 2003). The axe-txe genes and upstream promoter region share $100 \%$ homology with the pRUM 


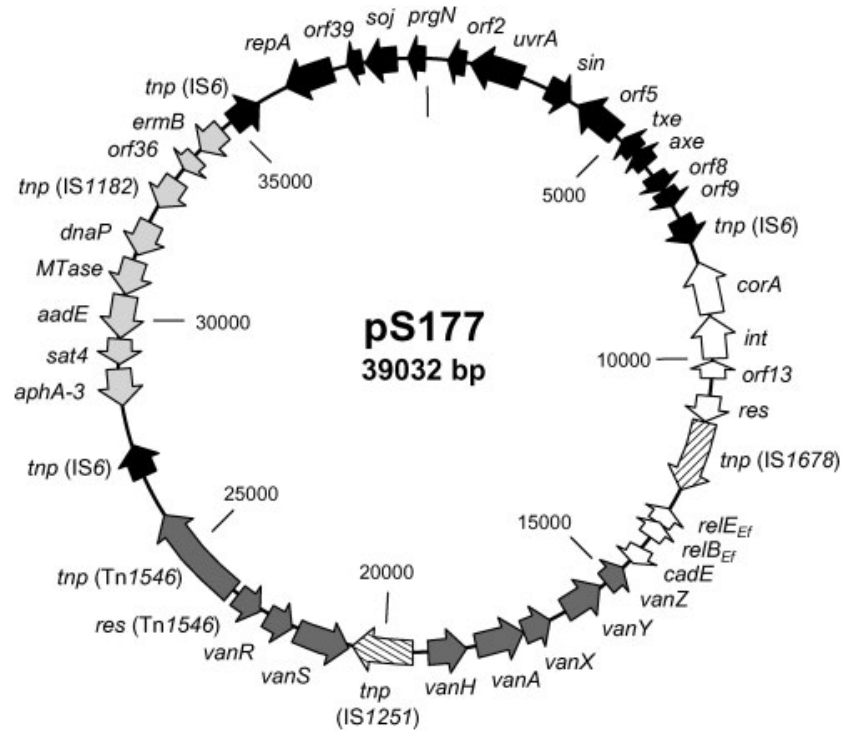

Fig. 1. Genetic organization and mosaic structure of multidrugresistant plasmid pS177. Coding sequences are indicated by arrows showing the predicted direction of transcription. Position 1 of pS177 was assigned as the same nucleotide position 1 of pRUM. The origins of the components of pS177 are shown by black, white or grey arrows: genes from pRUM, black; genes from p5753cA, white; solitary insertion elements, hatched; VanA-type glycopeptide resistance gene cassette, dark grey; $S$. intermedius resistance gene cassette, light grey.

sequence, suggesting that this TA system is functional (Grady \& Hayes, 2003). Plasmid pS177 harbours a gene cassette from Staphylococcus intermedius (GenBank accession no. AF299292), which confers resistance to streptothricin, streptomycin, kanamycin and erythromycin (Boerlin et al., 2001). pRUM carries a nearly identical gene cassette in which the aphA-3 gene encoding kanamycin resistance is truncated (Grady \& Hayes, 2003). The full-length S. intermedius resistance gene cassette is also carried on the enterococcal plasmids pRE25 (Schwarz et al., 2001) and p5753cB.

Additionally, vancomycin resistance is encoded by the VanA-type glycopeptide resistance determinant Tn1546, observed on many plasmids identified in VRE, including plasmids pVEF3 (Sletvold et al., 2008), p5753cA and pIP816 (GenBank accession no. AM932524). However, the Tn 1546 cassette on pS177 contains the insertion element IS 1251 between vanS and vanH. This unusual vanA cluster type has been observed previously (Camargo et al., 2004; Handwerger \& Skoble, 1995; Handwerger et al., 1995) and is also present on the enterococcal plasmid p5753cA, which carries a truncated vanA-type gene cassette with IS1251 in the same position as observed in $\mathrm{pS} 177$.

Plasmid pS177 shares 12748 bp (32.6\%) with p5753cA, including the putative RelBE TA system homologue from Ent. faecium, which we designate relBE $E_{E f}$ The ORFs encoding $\operatorname{RelB}_{E f}$ and $\operatorname{RelE}_{E f}$ were identified based on their homology with $\mathrm{p} 5753 \mathrm{cA}$, in which their putative gene products were annotated as hypothetical proteins. A BLASTP search of the amino acids encoded by $r e l E_{E f}$ showed up to $100 \%$ identity with a variety of Ent. faecium hypothetical proteins, as well as $53 \%$ amino acid identity with the RelE protein from Lactobacillus antri (Altschul et al., 1990). The BLASTP search of the amino acids encoded by $r e l B_{E f}$ resulted in hits sharing up to $100 \%$ homology with other Ent. faecium hypothetical proteins, as well as $79 \%$ amino acid identity with the Ent. faecalis AbrB family antitoxin component.

\section{Transcription of axe-txe in VRE clinical isolates}

To determine whether the mRNA transcript coding for the Axe-Txe proteins is produced in VRE strains previously shown by PCR to carry axe-txe (Moritz \& Hergenrother, 2007a), RT-PCR was performed from total mRNA isolated from six VRE clinical isolates. As shown in Fig. 2(a), all six isolates (C29113, S34, S177, SL242, SL266 and SL745) produce the axe-txe transcript. RT-PCR analysis was also performed on total RNA isolated from the plasmid-free Ent. faecium strain BM4105-RF, which does not contain the axe-txe genes, and no axe-txe transcript was detected (Fig. 2a). To ensure that the observed RT-PCR products were not due to DNA contamination, controls were performed in which the reverse transcriptase enzyme was not added, but all other components (including thermostable DNA polymerase and primers for axe-txe) were included. As shown in Fig. 2(b), no amplification product is observed under these conditions, confirming that the products seen by RT-PCR were due to the presence of transcript and not DNA contamination. Finally, RT-PCR with primers for the enterococcal elongation factor tuf gave the expected positive result for all seven strains examined (Fig. 2c) (Garcia-Migura et al., 2007). Thus, RT-PCR analysis demonstrated that the axe-txe transcript is synthesized in VRE clinical isolates carrying the axe-txe genes.

\section{Txe expression inhibits global protein synthesis}

As sequencing of pS177 and RT-PCR analysis of six VRE isolates revealed that axe-txe is present and transcribed in VRE, we sought to determine the mechanism by which Txe exerts its toxic activity. Such information could be exploited in the development of TA-specific antimicrobial therapies. Txe mechanistic experiments began by assessing the toxin's effect on global biosynthetic pathways in the cell. Radiolabel incorporation assays were carried out with $\left[{ }^{3} \mathrm{H}\right]$ thymidine to measure DNA synthesis, $\left[{ }^{3} \mathrm{H}\right]$ uridine to measure RNA synthesis and $\left[{ }^{3} \mathrm{H}\right] \mathrm{leucine}$ to measure protein synthesis upon induction of $\mathrm{Txe}^{-} \mathrm{His}_{6}$ expression with IPTG in E. coli Rosetta BL21(DE3). As shown in Fig. 3(a, b), levels of DNA and RNA synthesis were not inhibited by the expression of Txe-His ${ }_{6}$ in E. coli. In contrast, the level of protein synthesis was significantly inhibited by the expression of Txe-His ${ }_{6}$ in E. coli (Fig. 3c). By 2 h post-induction, 
Table 1. ORFs of plasmid pS177

\begin{tabular}{|c|c|c|c|c|c|c|}
\hline ORF $^{*}$ & Gene & \multicolumn{2}{|c|}{ Nucleotide position } & $\begin{array}{c}\text { Protein } \\
\text { length } \\
\text { (aa) }\end{array}$ & Database match (GenBank accession no.) & $\begin{array}{c}\text { Amino acid } \\
\text { identity } \\
(\%)\end{array}$ \\
\hline $1 c$ & $\operatorname{prgN}$ & 1 & 291 & 97 & pRUM PrgN (AAO52827) & 100 \\
\hline $2 c$ & orf 2 & 603 & 980 & 126 & pRUM conserved hypothetical protein, Ent. faecium (AAO52828) & 100 \\
\hline $5 c$ & orf5 & 3500 & 4504 & 335 & pRUM hypothetical protein (AAO52831) & 100 \\
\hline $6 \mathrm{c}$ & txe & 4963 & 5220 & 86 & pRUM Txe, toxin component of TA system (AAO52832) & 100 \\
\hline $7 \mathrm{c}$ & axe & 5213 & 5482 & 90 & pRUM Axe, antitoxin component of TA system (AAO52833) & 100 \\
\hline 8 & orf8 & 5824 & 6126 & 101 & pRUM conserved hypothetical protein (AAO52834) & 100 \\
\hline 9 & orf9 & 6169 & 6387 & 73 & pRUM conserved hypothetical protein (AAO52835) & 100 \\
\hline 10 & $\operatorname{tnp}$ (IS6) & 6559 & 7245 & 229 & pRUM IS6 transposase (AAO52848) & 100 \\
\hline $13 \mathrm{c}$ & orf13 & 10026 & 10156 & 43 & p5753cA hypothetical protein (ADA62235) & 100 \\
\hline 14 & res & 10585 & 11148 & 188 & p5753cA resolvase, $\mathrm{N}$-terminal domain (ADA62236) & 100 \\
\hline 15 & $\operatorname{tnp}($ IS 1678) & 11336 & 12655 & 440 & Ent. faecium transposase, IS1678 (AAW32124) & 99 \\
\hline $16 c$ & relEEf & 13111 & 13398 & 96 & $\begin{array}{l}\text { Lactobacillus antri RelE-like toxin component of TA system } \\
\text { (ZP_05745775) }\end{array}$ & 53 \\
\hline $17 \mathrm{c}$ & relBEf & 13388 & 13717 & 110 & $\begin{array}{l}\text { Ent. faecalis Abr-family antitoxin component of TA system } \\
\text { (ZP_06623423) }\end{array}$ & 79 \\
\hline 18 & $c a d E$ & 14022 & 14351 & 110 & p5753cA cadmium efflux system accessory protein (ADA62239) & 100 \\
\hline $19 \mathrm{c}$ & $\operatorname{van} Z$ & 14638 & 15123 & 162 & Tn1546 VanZ, teicoplanin resistance protein (AAA65959) & 100 \\
\hline $20 \mathrm{c}$ & $\operatorname{van} Y$ & 15276 & 16187 & 304 & Tn1546 VanY, truncated carboxypeptidase (AAA65958) & 99 \\
\hline $21 \mathrm{c}$ & $\operatorname{van} X$ & 16615 & 17223 & 203 & Tn1546 VanX, D-Ala-D-Ala dipeptidase (AAA65957) & 99 \\
\hline 29 & $\operatorname{tnp}(\mathrm{IS} 6)$ & 26661 & 27347 & 229 & pRUM IS6 transposase (AAO52854) & 100 \\
\hline $30 \mathrm{c}$ & $a p h-3$ & 28195 & 28980 & 262 & $\begin{array}{l}\text { S. intermedius Aph-3, aminoglycoside phosphotransferase } \\
\text { (AAG42234) }\end{array}$ & 100 \\
\hline $31 \mathrm{c}$ & sat4 & 29082 & 29612 & 177 & S. intermedius Sat4, streptothricin acetyltransferase (AAG42233) & 100 \\
\hline $32 \mathrm{c}$ & aadE & 29621 & 30529 & 303 & S. intermedius AadE, streptomycin adenyltransferase (AAG42232) & 100 \\
\hline $33 \mathrm{c}$ & MTase & 30562 & 31296 & 245 & Ent. faecium methyltransferase (ZP_00603123) & 100 \\
\hline $34 \mathrm{c}$ & dnaP & 31277 & 32146 & 290 & Ent. faecium DNA polymerase, beta-like region (ZP_00603124) & 100 \\
\hline $35 \mathrm{c}$ & $\operatorname{tnp}($ IS 1182) & 32521 & 33195 & 225 & S. intermedius transposase, IS1182 (AAG42229) & 99 \\
\hline $36 \mathrm{c}$ & $\operatorname{orf36}$ & 33652 & 33783 & 44 & S. intermedius orf3 (AAG42228) & 100 \\
\hline $37 \mathrm{c}$ & ermB & 33788 & 34525 & 246 & S. intermedius ErmB, erythromycin resistance methylase (AAG42227) & 100 \\
\hline 38 & $\operatorname{tnp}$ (IS6) & 34873 & 35559 & 229 & pRUM IS6 transposase (AAO52854) & 100 \\
\hline $39 \mathrm{c}$ & repA & 36175 & 37215 & 347 & pRUM putative RepA replication protein (AAO52855) & 100 \\
\hline $40 \mathrm{c}$ & orf 40 & 37564 & 37890 & 109 & pRUM hypothetical protein (AAO52856) & 100 \\
\hline $41 \mathrm{c}$ & soj & 37877 & 38680 & 268 & pRUM Soj partitioning protein (AAO52857) & 100 \\
\hline
\end{tabular}

${ }^{\star}$ ORFs predicted to be transcribed on the complementary strand are denoted with ' $c$ '.

the amount of $\left[{ }^{3} \mathrm{H}\right]$ leucine incorporation measured was greatly reduced in cells receiving IPTG compared with cells that did not receive IPTG. Shorter time points $(5,10,15$ and
$30 \mathrm{~min}$ ) were investigated to determine how quickly expression of Txe-His ${ }_{6}$ inhibited protein synthesis; however, differences in $\left[{ }^{3} \mathrm{H}\right]$ leucine incorporation were not observed 


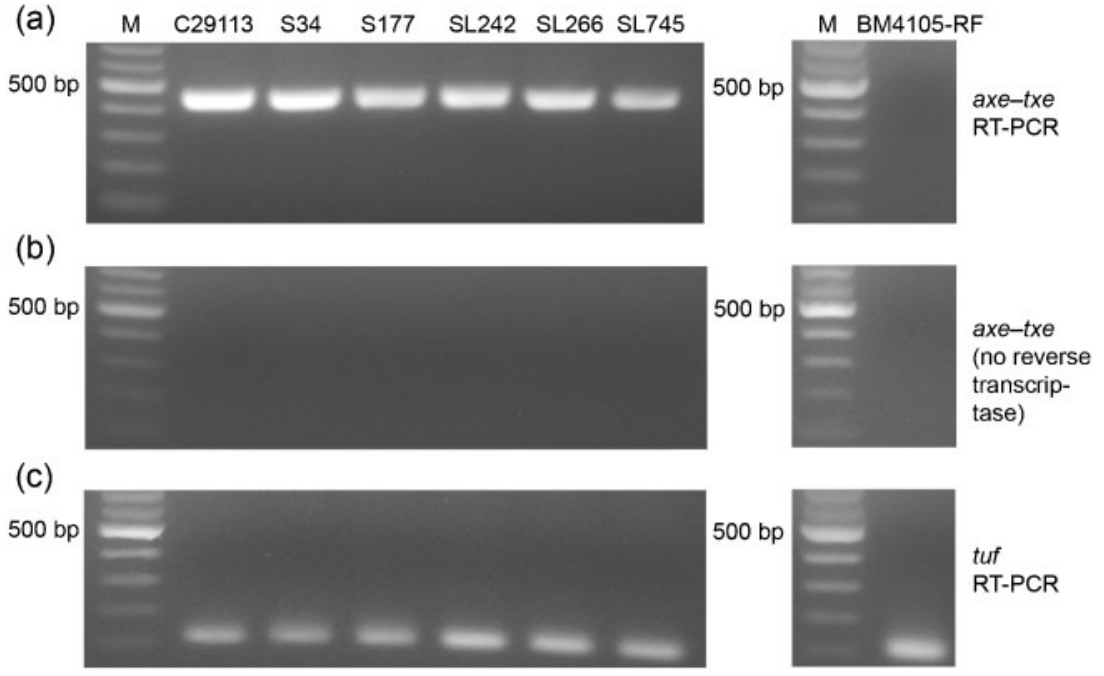

Fig. 2. RT-PCR analysis of six VRE isolates and a plasmid-free enterococcal strain (BM4105-RF). The VRE isolates tested were C29113, S34, S177, SL242, SL266 and SL745. (a) RT-PCR with primers complementary to axe-txe (product size $=447 \mathrm{bp}$ ). (b) Controls for DNA contamination, in which reverse transcriptase was omitted from the reaction mix. (c) RT-PCR with primers complementary to the enterococci tuf gene (product size=112 bp). Lane M, DNA molecular mass markers. until $60 \mathrm{~min}$ post-induction (Supplementary Fig. S1, available with the online version of this paper). Growth of E. coli harbouring the pET21a-txe-His ${ }_{6}$ plasmid in liquid culture was also examined; induction of Txe-His ${ }_{6}$ expression with IPTG in E. coli resulted in a decrease in the viable cell count (Supplementary Fig. S2).

To determine whether the inhibition of protein synthesis observed was specific for the expression of Txe-His radiolabel incorporation assays were performed with $\left[{ }^{3} \mathrm{H}\right]$ leucine and E. coli carrying the pET21a-axe-His 6 plasmid or the empty pET21a vector. As shown in Supplementary Fig. S3(a, b), the level of protein synthesis was not inhibited by the expression of Axe-His ${ }_{6}$ in E. coli or when IPTG was added to cells carrying the empty vector. A direct comparison of levels of $\left[{ }^{3} \mathrm{H}\right]$ leucine incorporation following addition of IPTG to E. coli with pET21a, pET21aaxe-His $_{6}$ and pET21a-txe-His 6 at the various time points examined indicated that there is considerable inhibition of protein synthesis by Txe-His 6 (Fig. 4).

\section{Txe inhibits protein synthesis in a cell-free system}

A cell-free system was used to examine further the inhibitory effect of $\mathrm{Txe}^{-\mathrm{His}_{6}}$ on protein synthesis. An E. coli T7 S30 extract system was preincubated with the pET21a-txe-His 6 plasmid to begin synthesis of the Txe$\mathrm{His}_{6}$ protein, followed by the addition of DNA encoding the reporter (pET28a-relB-His ${ }_{6}$ or pRSF1b-His ${ }_{6}-l p p$ ) to allow synthesis of RelB-His ${ }_{6}$ (the antitoxin of the RelBE TA system) or the major lipoprotein, Lpp, of the E. coli outer membrane (Christensen \& Gerdes, 2003; Gotfredsen \& Gerdes, 1998). Txe-His ${ }_{6}$ inhibited the synthesis of RelBHis $_{6}$ (Fig. 5a, lane 3) and His ${ }_{6}$-Lpp (Fig. 5b, lane 3). When $\mathrm{His}_{6}-$ Axe or Axe-His ${ }_{6}$ was synthesized instead of Txe-His protein synthesis of RelB-His ${ }_{6}$ and $\mathrm{His}_{6}-\mathrm{Lpp}$ was not inhibited (Fig. 5a, b, lane 4). Interestingly, both tagged versions of the antitoxin were unable to significantly prevent protein synthesis inhibition by Txe-His ${ }_{6}$ (data not shown). This may be the result of Txe-His inhibiting $_{6}$ protein synthesis of the antitoxin as well as RelB-His ${ }_{6}$ and $\mathrm{His}_{6}$-Lpp, or interference of the $\mathrm{His}_{6}$-tag on Axe with its ability to bind the toxin.

\section{Txe cleaves mRNA in a sequence-specific manner}

In vivo primer extension analysis was used to determine if Txe-mediated protein synthesis inhibition is achieved via mRNA cleavage in the cell. Cleavage of the $5^{\prime}$ end of $l p p$ mRNA was chosen for analysis given its frequent use as an RNA substrate for both Northern blot analysis and primer extension analysis in mechanistic investigations of other TA system toxins (Christensen-Dalsgaard \& Gerdes, 2008; Christensen \& Gerdes, 2003; Christensen et al., 2003; Zhang et al., 2004).

To perform primer extension analysis in cell culture, RNA was isolated from E. coli Rosetta BL21(DE3) cultures before and after induction of txe expression by IPTG. As shown in Fig. 6, induction of Txe-His $_{6}$ expression led to the disappearance of the full-length $l p p$ mRNA band and the appearance of a major cleavage band as early as $30 \mathrm{~min}$ post-induction (Fig. 6). The major cleavage band appeared three bases downstream of the A of the AUG start codon. These results suggest that Txe-His ${ }_{6}$ cleaves mRNA and that this RNase activity may lead to the protein synthesis inhibition observed upon induction of Txe-His ${ }_{6}$ expression in the macromolecular synthesis assays and cell-free protein synthesis assays.

\section{DISCUSSION}

The Axe-Txe TA system was first discovered on a multidrug-resistant plasmid, pRUM, in a vancomycinresistant Ent. faecium clinical isolate (Grady \& Hayes, 2003). Axe-Txe was one of the first proteic TA systems to be characterized from Gram-positive bacteria; it was also notable in that axe-txe was discovered on a bacterial 

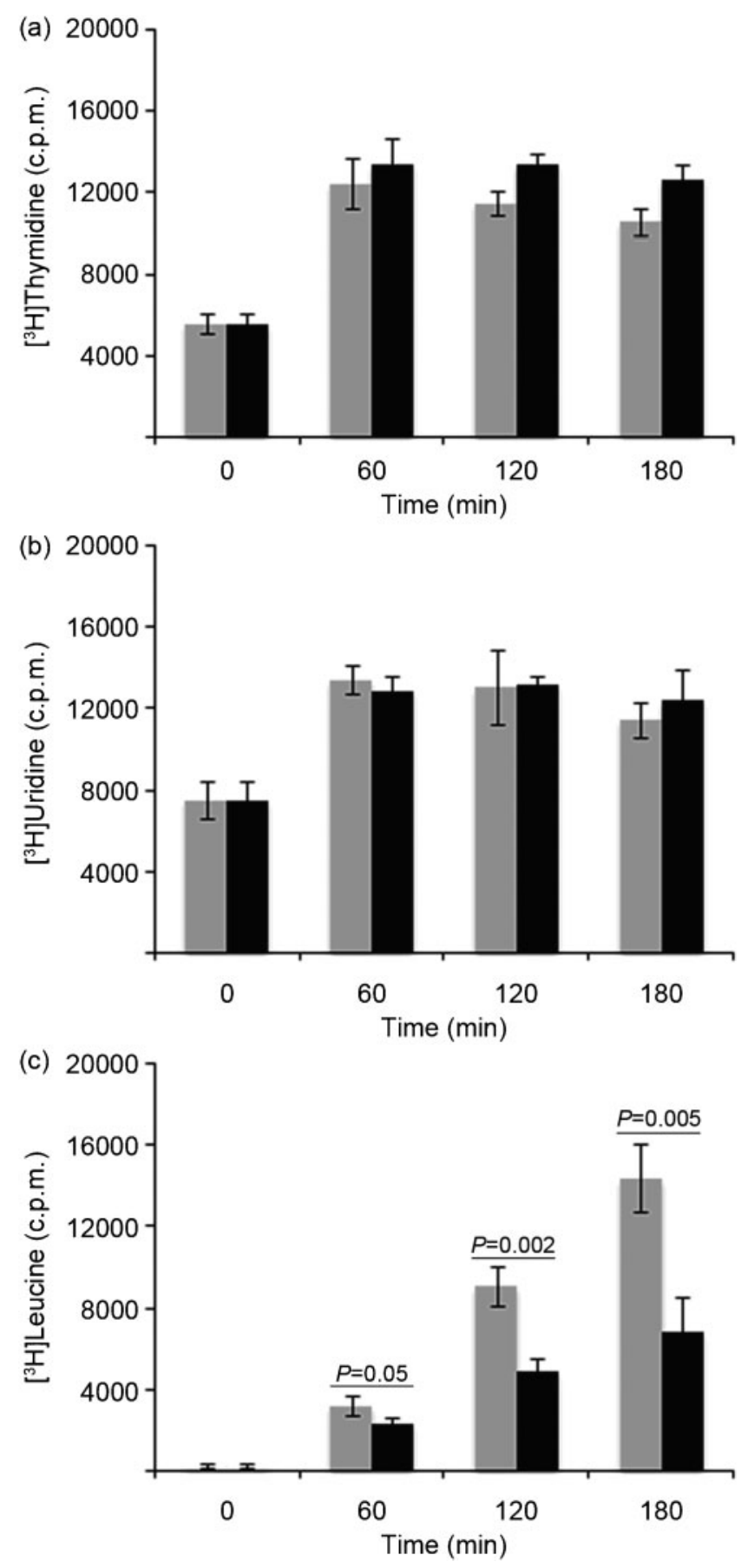

Fig. 3. DNA, RNA and protein synthesis following IPTG induction of $\mathrm{Txe}^{-} \mathrm{His}_{6}$, as assessed immediately before and following addition of 0 (grey bars) or 0.05 (black bars) mM IPTG to E. coli Rosetta BL21(DE3) carrying the pET21a-txe-His ${ }_{6}$ plasmid. Incorporation of $\left[{ }^{3} \mathrm{H}\right]$ thymidine $(\mathrm{a}),\left[{ }^{3} \mathrm{H}\right]$ uridine (b) and $\left[{ }^{3} \mathrm{H}\right]$ leucine (c). Results are the mean of three independent experiments. Error bars, SD; $P$, statistical significance between designated groups.

plasmid, whereas most TA systems were discovered on bacterial chromosomes. Preliminary analysis of Axe-Txe demonstrated that it functions as a characteristic TA

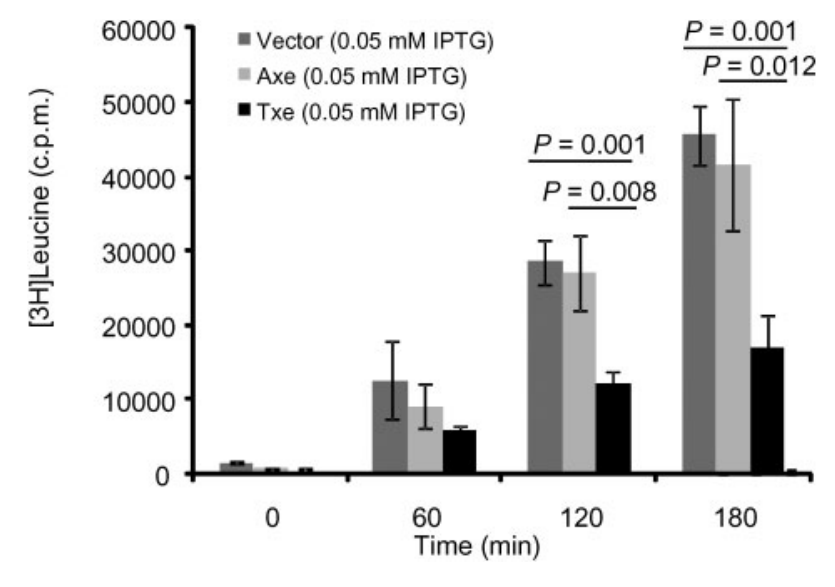

Fig. 4. Protein synthesis following IPTG induction of Txe-His Axe-His ${ }_{6}$ and empty pET21a vector. Incorporation of $\left[{ }^{3} \mathrm{H}\right]$ leucine immediately before and following addition of $0.05 \mathrm{mM}$ IPTG to $E$. coli Rosetta BL21(DE3) carrying pET21a, pET21a-txe-His ${ }_{6}$ or pET21a-axe-His 6 . Results are the mean of three independent experiments. Error bars, SD; $P$, statistical significance between designated groups.

system: expression of Txe is toxic to cells, expression of Axe alleviates Txe-induced toxicity and Axe-Txe increases the segregational stability of plasmids (Grady \& Hayes, 2003). Due to the prevalence of the axe-txe genes encoded on plasmids in enterococcal isolates (Moritz \& Hergenrother, 2007a; Rosvoll et al., 2010), activation of Txe presents an attractive antimicrobial strategy. However, a lack of biochemical characterization of the Axe-Txe proteins, including knowledge of the biological target or mechanism of action of Txe, hampers exploration of Axe-Txe as an antimicrobial target.

In this study, the complete nucleotide sequence of the $39 \mathrm{~kb}$ non-conjugative plasmid pS177 isolated from a VRE clinical strain S177 was determined. A BLAST analysis revealed extensive homology to known sequences, including the enterococcal plasmid pRUM, the vanA-type glycopeptide resistance determinant $\operatorname{Tn} 1546$ and the $S$. intermedius resistance gene cassette (Altschul et al., 1990). Thus, pS177 appears to have arisen from multiple recombination events between smaller plasmids and mobile genetic elements. This is the first report, to our knowledge, of a completely sequenced VRE plasmid that harbours a full-length vanA cassette containing the insertion element IS 1251 between vanS and vanH. Additionally, plasmid pS177 confers resistance to vancomycin, kanamycin, streptomycin, streptothricin and erythromycin and, indeed, VRE strain S177 was resistant to gentamicin, erythromycin and vancomycin (Moritz \& Hergenrother, 2007a). The presence of TA systems on pS177, including axe-txe and $r e l B E_{E f}$, probably enhances plasmid stability and enables the persistence of this multidrug-resistant plasmid in clinical isolates of VRE. This is also the first report of a completely sequenced plasmid carrying both the VanA- 


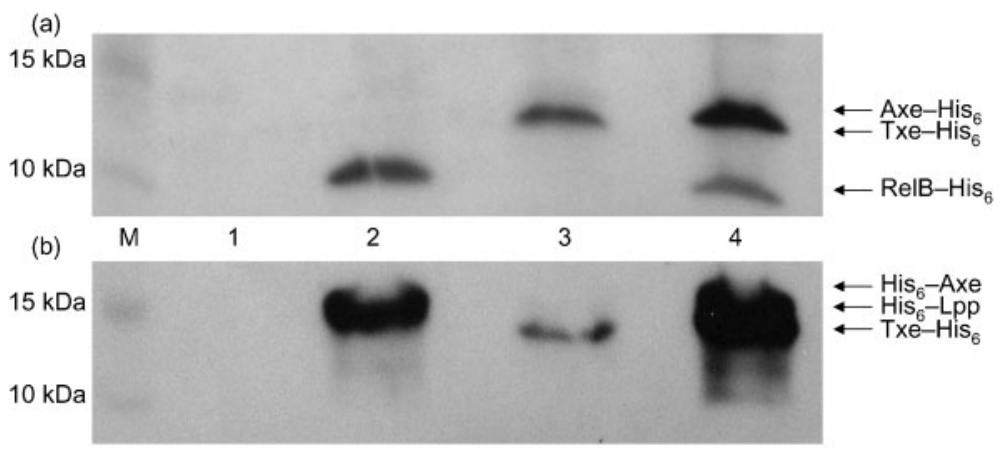

Fig. 5. Effect of $\mathrm{Txe}^{-} \mathrm{His}_{6}, \mathrm{Axe}-\mathrm{His}_{6}$ and $\mathrm{His}_{6}-$ Axe on cell-free protein synthesis. (a) Western blot with HisProbe-HRP of cell-free protein synthesis reactions with no DNA added (lane 1), pET28a-re/B-His ${ }_{6}$ DNA added (2), pET28are/B-His 6 and $\mathrm{pET} 21 \mathrm{a}-\mathrm{txe}_{\mathrm{H}}-\mathrm{His}_{6}$ DNA added (3), and pET28a-re/B-His ${ }_{6}$ and pET21a-axe$\mathrm{His}_{6}$ DNA added (4). (b) Western blot with HisProbe-HRP of cell-free protein synthesis reactions with no DNA added (lane 1), pRSF1b-His ${ }_{6}-$ Ipp DNA added (2), pRSF1b$\mathrm{His}_{6}-$ Ipp and pET21a-txe-His ${ }_{6}$ DNA added (3), and pRSF $1 b-\mathrm{His}_{6}-\mathrm{Ipp}$ and pACYCDuet $1-\mathrm{His}_{6}{ }^{-}$ axe DNA added (4). M, Marker lane.

type resistance determinant and axe-txe. In addition, it is shown here for the first time to our knowledge that the axe-txe transcript is produced in VRE clinical isolates. The conclusive link between the pRUM-like replicon, axe-txe, the vanA-type resistance determinant (as demonstrated from sequencing) and the presence of axe-txe transcripts in VRE clinical isolates further supports the importance of axe-txe in the maintenance of plasmids coding for multidrug resistance, and bolsters the notion of targeting axe-txe for antimicrobial development (Moritz \& Hergenrother, 2007b; Rosvoll et al., 2010).

Txe shares significant sequence similarity with the YoeB toxin, which is part of the RelE toxin superfamily, and is structurally related to the archaeal RelE monomer (Francuski \& Saenger,

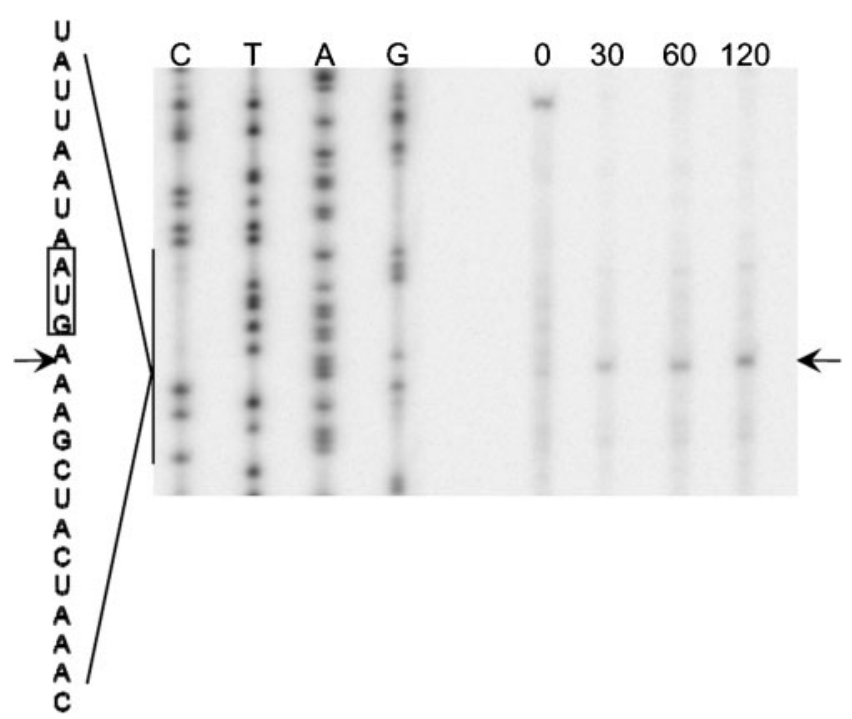

Fig. 6. Txe-induced cleavage of $I p p$ mRNA. The $5^{\prime}$ end of $I p p$ mRNA was mapped by using the primer Ipp 21. Numbers indicate times $(\mathrm{min})$ at which mRNA was harvested after the addition of IPTG. The major cleavage site is indicated by an arrow. The sequence around the major cleavage site is shown to the side, with the cleavage site again indicated by an arrow.
2009; Kamada, 2005). The RelE and YoeB toxins from E. coli and two YoeB homologues in Staphylococcus aureus have been shown to inhibit protein synthesis through mRNA cleavage (Grady \& Hayes, 2003; Zhang \& Inouye, 2009; Yoshizumi et al., 2009; Kamada, 2005). The results of the macromolecular synthesis assays and cell-free protein synthesis assays described herein indicate that Txe significantly inhibits protein synthesis. The results of primer extension analysis indicate that Txe cleaves mRNA, and this activity is probably the mechanism by which Txe inhibits protein synthesis.

The two major mechanisms of action for toxins of TA systems are the inhibition of DNA gyrase and the cleavage of cellular RNA. There is reasonable amino acid sequence similarity between Txe and the YoeB RNase (Grady \& Hayes, 2003); however, it has been noted that these two toxins have very different effects on cells, with yoeB expression dramatically reducing viable cell numbers, whereas txe expression halts growth but does not induce death (Grady \& Hayes, 2003). Although structural and sequence similarity to other toxins can be informative in discerning mode of action, it can be misleading as well. For example, significant structural similarity exists between the gyrase poison $\mathrm{CcdB}$ and the RNase MazF (Buts et al., 2005). Thus, it was not obvious a priori under which category Txe would fall.

With the completion of the experiments described herein, it is now apparent that Txe is an RNase harbouring similarities to YoeB and sharing some, but not all, characteristics with other members of the RelE superfamily. Txe cleaved $l p p$ mRNA three bases downstream of the A of the AUG start codon, similar to what has been observed with the YoeB toxin (Yoshizumi et al., 2009; Zhang \& Inouye, 2009). In contrast, the RelE toxin has been shown to cleave mRNA at both sense and stop codons, with a strong preference for cleavage of the stop codon UAG between the second and third bases (Christensen \& Gerdes, 2003; Pedersen et al., 2003).

The data presented here indicate that the Txe toxin is an RNase and inhibits protein synthesis, activities which may play a role in the ability of axe-txe to stabilize plasmids in 
enterococci, including plasmids harbouring the genes for antibiotic resistance (Grady \& Hayes, 2003). As axe-txe appears to be widespread in VRE clinical isolates (Moritz \& Hergenrother, 2007a; Rosvoll et al., 2010), the artificial activation of Txe could be an effective antibacterial strategy.

\section{ACKNOWLEDGEMENTS}

This work was supported by the National Institutes of Health (2R01GM068385). E.M.H. and J.J.W. were partially supported by a National Institutes of Health Cell and Molecular Biology Training grant (T32 GM007283). We thank Laura Guest for plasmid sequencing and assembly.

\section{REFERENCES}

Aizenman, E., Engelberg-Kulka, H. \& Glaser, G. (1996). An Escherichia coli chromosomal "addiction module" regulated by guanosine [corrected] 3',5'-bispyrophosphate: a model for programmed bacterial cell death. Proc Natl Acad Sci U S A 93, 6059-6063.

Altschul, S. F., Gish, W., Miller, W., Myers, E. W. \& Lipman, D. J. (1990). Basic local alignment search tool. J Mol Biol 215, 403-410.

Anantharaman, V. \& Aravind, L. (2003). New connections in the prokaryotic toxin-antitoxin network: relationship with the eukaryotic nonsense-mediated RNA decay system. Genome Biol 4, R81.

Baldassarri, L., Bertuccini, L., Creti, R., Orefici, G., Dicuonzo, G., Gherardi, G., Venditti, M. \& Di Rosa, R. (2005). Clonality among Enterococcus faecium clinical isolates. Microb Drug Resist 11, 141-145.

Bernard, P. \& Couturier, M. (1992). Cell killing by the F plasmid CcdB protein involves poisoning of DNA-topoisomerase II complexes. J Mol Biol 226, 735-745.

Boerlin, P., Burnens, A. P., Frey, J., Kuhnert, P. \& Nicolet, J. (2001). Molecular epidemiology and genetic linkage of macrolide and aminoglycoside resistance in Staphylococcus intermedius of canine origin. Vet Microbiol 79, 155-169.

Buts, L., Lah, J., Dao-Thi, M. H., Wyns, L. \& Loris, R. (2005). Toxinantitoxin modules as bacterial metabolic stress managers. Trends Biochem Sci 30, 672-679.

Camargo, I. L., Del Peloso, P. F., Da Costa Leite, C. F., Goldman, G. H. \& Darini, A. L. (2004). Identification of an unusual VanA element in glycopeptide-resistant Enterococcus faecium in Brazil following international transfer of a bone marrow transplant patient. Can J Microbiol 50, 767-770.

Christensen, S. K. \& Gerdes, K. (2003). RelE toxins from bacteria and Archaea cleave mRNAs on translating ribosomes, which are rescued by tmRNA. Mol Microbiol 48, 1389-1400.

Christensen, S. K., Mikkelsen, M., Pedersen, K. \& Gerdes, K. (2001). RelE, a global inhibitor of translation, is activated during nutritional stress. Proc Natl Acad Sci U S A 98, 14328-14333.

Christensen, S. K., Pedersen, K., Hansen, F. G. \& Gerdes, K. (2003). Toxin-antitoxin loci as stress-response-elements: ChpAK/MazF and ChpBK cleave translated RNAs and are counteracted by tmRNA. J Mol Biol 332, 809-819.

Christensen-Dalsgaard, M. \& Gerdes, K. (2008). Translation affects YoeB and MazF messenger RNA interferase activities by different mechanisms. Nucleic Acids Res 36, 6472-6481.

Christensen-Dalsgaard, M., Overgaard, M., Winther, K. S. \& Gerdes, K. (2008). RNA decay by messenger RNA interferases. Methods Enzymol 447, 521-535.
DeNap, J. C. \& Hergenrother, P. J. (2005). Bacterial death comes full circle: targeting plasmid replication in drug-resistant bacteria. $\mathrm{Org}$ Biomol Chem 3, 959-966.

Deshpande, L. M., Fritsche, T. R., Moet, G. J., Biedenbach, D. J. \& Jones, R. N. (2007). Antimicrobial resistance and molecular epidemiology of vancomycin-resistant enterococci from North America and Europe: a report from the SENTRY antimicrobial surveillance program. Diagn Microbiol Infect Dis 58, 163-170.

Dowzicky, M. J. \& Park, C. H. (2008). Update on antimicrobial susceptibility rates among gram-negative and Gram-positive organisms in the United States: results from the Tigecycline Evaluation and Surveillance Trial (TEST) 2005 to 2007. Clin Ther 30, 2040-2050.

Engelberg-Kulka, H. \& Glaser, G. (1999). Addiction modules and programmed cell death and antideath in bacterial cultures. Annu Rev Microbiol 53, 43-70.

Engelberg-Kulka, H., Sat, B., Reches, M., Amitai, S. \& Hazan, R. (2004). Bacterial programmed cell death systems as targets for antibiotics. Trends Microbiol 12, 66-71.

Fico, S. \& Mahillon, J. (2006). TasA-tasB, a new putative toxinantitoxin (TA) system from Bacillus thuringiensis pGI1 plasmid is a widely distributed composite mazE-doc TA system. BMC Genomics 7, 259.

Francuski, D. \& Saenger, W. (2009). Crystal structure of the antitoxin-toxin protein complex RelB-RelE from Methanococcus jannaschii. J Mol Biol 393, 898-908.

Garcia-Migura, L., Liebana, E., Jensen, L. B., Barnes, S. \& Pleydell, E. (2007). A longitudinal study to assess the persistence of vancomycinresistant Enterococcus faecium (VREF) on an intensive broiler farm in the United Kingdom. FEMS Microbiol Lett 275, 319-325.

Gerdes, K., Rasmussen, P. B. \& Molin, S. (1986). Unique type of plasmid maintenance function: postsegregational killing of plasmidfree cells. Proc Natl Acad Sci U S A 83, 3116-3120.

Gotfredsen, M. \& Gerdes, K. (1998). The Escherichia coli relBE genes belong to a new toxin-antitoxin gene family. Mol Microbiol 29, 10651076.

Grady, R. \& Hayes, F. (2003). Axe-Txe, a broad-spectrum proteic toxin-antitoxin system specified by a multidrug-resistant, clinical isolate of Enterococcus faecium. Mol Microbiol 47, 1419-1432.

Guardabassi, L. \& Dalsgaard, A. (2004). Occurrence, structure, and mobility of Tn1546-like elements in environmental isolates of vancomycin-resistant enterococci. Appl Environ Microbiol 70, 984990.

Handwerger, S. \& Skoble, J. (1995). Identification of chromosomal mobile element conferring high-level vancomycin resistance in Enterococcus faecium. Antimicrob Agents Chemother 39, 2446-2453.

Handwerger, S., Skoble, J., Discotto, L. F. \& Pucci, M. J. (1995). Heterogeneity of the vanA gene cluster in clinical isolates of enterococci from the northeastern United States. Antimicrob Agents Chemother 39, 362-368.

Hayes, F. (2003). Toxins-antitoxins: plasmid maintenance, programmed cell death, and cell cycle arrest. Science 301, 1496-1499.

Hidron, A. I., Edwards, J. R., Patel, J., Horan, T. C., Sievert, D. M., Pollock, D. A. \& Fridkin, S. K. (2008). NHSN annual update: antimicrobial-resistant pathogens associated with healthcare-associated infections: annual summary of data reported to the National Healthcare Safety Network at the Centers for Disease Control and Prevention, 2006-2007. Infect Control Hosp Epidemiol 29, 9961011.

Jiang, Y., Pogliano, J., Helinski, D. R. \& Konieczny, I. (2002). ParE toxin encoded by the broad-host-range plasmid RK2 is an inhibitor of Escherichia coli gyrase. Mol Microbiol 44, 971-979. 
JMI (2009). Susceptibility of Gram-positive pathogens. http://www. gp-pathogens.com/data/default.cfm.

Kamada, K. \& Hanaoka, F. (2005). Conformational change in the catalytic site of the ribonuclease YoeB toxin by YefM antitoxin. Mol Cell 19, 497-510.

Kitami, Y. \& Hiwada, K. (1999). Vascular disease: molecular biology and gene therapy protocols. In Methods in Molecular Medicine, pp. 133-142. Edited by A. H. Baker. Bristol: Bristol Heart Institute, University of Bristol.

Low, D. E., Keller, N., Barth, A. \& Jones, R. N. (2001). Clinical prevalence, antimicrobial susceptibility, and geographic resistance patterns of enterococci: results from the SENTRY Antimicrobial Surveillance Program, 1997-1999. Clin Infect Dis 32 (Suppl. 2), S133S145.

Makarova, K. S., Wolf, Y. I. \& Koonin, E. V. (2009). Comprehensive comparative-genomic analysis of type 2 toxin-antitoxin systems and related mobile stress response systems in prokaryotes. Biol Direct $\mathbf{4}$ 19.

Miallau, L., Faller, M., Chiang, J., Arbing, M., Guo, F., Cascio, D. \& Eisenberg, D. (2009). Structure and proposed activity of a member of the VapBC family of toxin-antitoxin systems. VapBC-5 from Mycobacterium tuberculosis. J Biol Chem 284, 276-283.

Moritz, E. M. \& Hergenrother, P. J. (2007a). Toxin-antitoxin systems are ubiquitous and plasmid-encoded in vancomycin-resistant enterococci. Proc Natl Acad Sci U S A 104, 311-316.

Moritz, E. M. \& Hergenrother, P. J. (2007b). The prevalence of plasmids and other mobile genetic elements in clinically important drug-resistant bacteria. In Antimicrobial Resistance in Bacteria, pp. 25-53. Edited by C. F. Amabile-Ceuvas. Norwich: Horizon Scientific Press.

Ogura, T. \& Hiraga, S. (1983). Mini-F plasmid genes that couple host cell division to plasmid proliferation. Proc Natl Acad Sci U S A 80, 4784-4788.

Owens, C. D. \& Stoessel, K. (2008). Surgical site infections: epidemiology, microbiology and prevention. J Hosp Infect $\mathbf{7 0}$ (Suppl. 2), 3-10.

Pandey, D. P. \& Gerdes, K. (2005). Toxin-antitoxin loci are highly abundant in free-living but lost from host-associated prokaryotes. Nucleic Acids Res 33, 966-976.

Pedersen, K., Zavialov, A. V., Pavlov, M. Y., Elf, J., Gerdes, K. \& Ehrenberg, M. (2003). The bacterial toxin RelE displays codonspecific cleavage of mRNAs in the ribosomal A site. Cell 112, 131-140.

Richards, M. J., Edwards, J. R., Culver, D. H. \& Gaynes, R. P. (2000). Nosocomial infections in combined medical-surgical intensive care units in the United States. Infect Control Hosp Epidemiol 21, 510-515.

Rosvoll, T. C., Pedersen, T., Sletvold, H., Johnsen, P. J., Sollid, J. E., Simonsen, G. S., Jensen, L. B., Nielsen, K. M. \& Sundsfjord, A. (2010). PCR-based plasmid typing in Enterococcus faecium strains reveals widely distributed pRE25-, pRUM-, pIP501- and pHTbetarelated replicons associated with glycopeptide resistance and stabilizing toxin-antitoxin systems. FEMS Immunol Med Microbiol 58, 254-268.

Sader, H. S. \& Jones, R. N. (2009). Antimicrobial susceptibility of Gram-positive bacteria isolated from US medical centers: results of the Daptomycin Surveillance Program (2007-2008). Diagn Microbiol Infect Dis 65, 158-162.

Sambrook, J. \& Russell, D. W. (2001). Molecular Cloning: a Laboratory Manual. Cold Spring Harbor, NY: Cold Spring Harbor Laboratory.

Schwarz, F. V., Perreten, V. \& Teuber, M. (2001). Sequence of the 50$\mathrm{kb}$ conjugative multiresistance plasmid pRE25 from Enterococcus faecalis RE25. Plasmid 46, 170-187.

Sletvold, H., Johnsen, P. J., Simonsen, G. S., Aasnaes, B., Sundsfjord, A. \& Nielsen, K. M. (2007). Comparative DNA analysis of two vanA plasmids from Enterococcus faecium strains isolated from poultry and a poultry farmer in Norway. Antimicrob Agents Chemother 51, 736-739.

Sletvold, H., Johnsen, P. J., Hamre, I., Simonsen, G. S., Sundsfjord, A. \& Nielsen, K. M. (2008). Complete sequence of Enterococcus faecium pVEF3 and the detection of an omega-epsilon-zeta toxin-antitoxin module and an ABC transporter. Plasmid 60, 75-85.

Strong, S. J., Ohta, Y., Litman, G. W. \& Amemiya, C. T. (1997). Marked improvement of PAC and BAC cloning is achieved using electroelution of pulsed-field gel-separated partial digests of genomic DNA. Nucleic Acids Res 25, 3959-3961.

Van Melderen, L. (2002). Molecular interactions of the CcdB poison with its bacterial target, the DNA gyrase. Int J Med Microbiol 291, 537-544.

Werner, G., Coque, T. M., Hammerum, A. M., Hope, R., Hryniewicz, W., Johnson, A., Klare, I., Kristinsson, K. G., Leclercq, R. \& other authors (2008). Emergence and spread of vancomycin resistance among enterococci in Europe. Euro Surveill 13, 19046.

Williams, J. J. \& Hergenrother, P. J. (2008). Exposing plasmids as the Achilles' heel of drug-resistant bacteria. Curr Opin Chem Biol 12, 389399.

Yoshizumi, S., Zhang, Y., Yamaguchi, Y., Chen, L., Kreiswirth, B. N. \& Inouye, M. (2009). Staphylococcus aureus YoeB homologues inhibit translation initiation. J Bacteriol 191, 5868-5872.

Zhang, Y. \& Inouye, M. (2009). The inhibitory mechanism of protein synthesis by YoeB, an Escherichia coli toxin. J Biol Chem 284, 66276638.

Zhang, J., Zhang, Y., Zhu, L., Suzuki, M. \& Inouye, M. (2004). Interference of mRNA function by sequence-specific endoribonuclease PemK. J Biol Chem 279, 20678-20684.

Edited by: K. E. Weaver 